\title{
Study of Laminar Convection Heat Transfer of Non-Newtonian Nanofluids in a Tube under Constant Heat Flux Using New Power-Law Relation
}

\author{
Morteza Bayareh $^{1}$, Nader Afshar ${ }^{2 *}$ \\ ${ }^{1}$ Department of Mechanical Engineering, Shahrekord University, Shahrekord 8818634141, Iran \\ ${ }^{2}$ Department of Chemical Engineering, Isfahan University of Technology, Isfahan 8415683111, Iran
}

Corresponding Author Email: n.afshar@ce.iut.ac.ir

https://doi.org/10.18280/ijht.380228

Received: 23 January 2019

Accepted: 14 March 2020

\section{Keywords:}

convection heat transfer, non-Newtonian

fluids, power-law relation, tube

\begin{abstract}
In this study, thermal and rheological behavior of non-Newtonian nanofluids in a tube is studied using a new power-law relation. The tube is under a constant heat flux and the viscosity of power-law non-Newtonian nanofluids is assumed to be a function of shear rate and temperature simultaneously. Fully developed velocity and uniform velocity profiles are considered as inlet boundary condition. It is demonstrated that the viscosity along the tube is affected by temperature and shear rate for fully developed and uniform flow profiles. Local heat transfer coefficient along the tube increases with the volume fraction, however volume fraction less than 3\% does not affect local heat transfer. It is demonstrated that local heat transfer and average Nusselt number are decreasing functions of Reynolds number. Contrary to the previous studies, average Nusselt number is a decreasing function of the volume fraction of nanoparticles. The Nusselt number is suggested to be a function of Peclet number when the temperature effects are considered in the power-law relation.
\end{abstract}

\section{INTRODUCTION}

In two past decades, nanofluids have been introduced and counted as advanced heat transfer fluids in several industrial applications such as chemical and petrochemical applications. Nanofluids are suspensions of nanoparticles in a base fluid which are uniform and stable [1,2]. Water, ethylene glycol and some oils are used as the base fluid. Researchers have investigated the rheological and thermal properties of nanofluids and presented several correlations to predict their properties such as viscosity, thermal conductivity, specific heat capacity and density [3-9]. For reliable design and optimization of process equipment, it is essential to know the information about the heat transfer rate for such liquids flowing through channels. Some researchers verified convective heat transfer of nanofluids in channels experimentally and numerically [10-19]. They presented correlations to predict hydrodynamic and heat transfer trends of nanofluids. Many researchers studied the laminar and turbulent flow of nanofluids in tubes with different cross section or tubes [10, 17-21]. Microchannels with different cross sections, tubes involving twisted tape inserts and corrugated tubes are some examples. Study of forced and natural convection heat transfer of non-Newtonian nanofluids have been recently performed by some researchers $[12,13,17$, 18]. Hojjat et al. [7] dispersed $\mathrm{CuO}$ nanoparticles in a 0.5 weight percent aqueous solution of carboxymethyl cellulose (CMC) to make a non-Newtonian nanofluid with different volume fractions. They studied rheological behavior of the flow and reported the viscosity of this nanofluid as a nonNewtonian power-law fluid for the temperature range of $278 \mathrm{~K}$ to $318 \mathrm{~K}$. Mariano et al. [9] investigated thermal conductivity, rheological behavior and density of non-Newtonian $\mathrm{SnO}_{2} /$ ethylene glycol nanofluid. Most of researchers investigated the rheological and thermal conductivity of nonNewtonian nanofluids and concluded a power-law behavior for these fluids [4-6]. Hojjat et al. [17] studied forced convection heat transfer of non-Newtonian nanofluids through a circular plain tube under constant heat flux in turbulent flow regime. They reported higher heat transfer coefficient for higher volume fractions of nanoparticles. While some researchers investigated the convection heat transfer of nonNewtonian nanofluids experimentally [10, 17], numerical simulations of non-Newtonian nanofluids flow were performed by many researchers [12, 13, 18]. Kamali and Binesh [22] studied the laminar flow of nanofluids in a 1.55 $\mathrm{mm}$ tube. They modeled thermal conductivity of nanofluids as fourth degree functions of temperature and viscosity as powerlaw fluid functions. Keshavarz Moraveji et al. [18] investigated Herschel-Bulkley non-Newtonian nanofluid flow in a $4.75 \mathrm{~mm}$ plain tube and presented a correlation to predict the Nusselt number. Esmaeilnejad et al. [12] investigated power-law non-Newtonian nanofluids in three different microchannels under constant heat fluxes. However, they did not consider thermal conductivity as a function of temperature.

To the best of our knowledge, the researchers have not considered the temperature influences on the viscosity. They assumed that the viscosity is only a function of shear rate while they were investigating the convective heat transfer. In this study, the viscosity of power-law nanofluids is assumed to be a function of shear rate and temperature simultaneously. Thermal conductivity of the nanofluids is a function of the temperature. Natural convection heat transfer characteristics of power-law nanofluids in a tube under constant heat flux are investigated. Hydrodynamically fully developed flow is compared with uniform velocity flow as inlet boundary conditions. Effects of nanoparticle volume fraction and Reynolds number on heat transfer are evaluated. In addition, a 
new sliding adaption (called boundary adaption method) is used for the simulation in this paper.

\section{PROBLEM DESCRIPTION}

A $1.55 \mathrm{~mm}$ diameter circular plain tube with $914.4 \mathrm{~mm}$ length is the computational domain which is shown in Figure 1. Garg et al. [10] used the same tube for their experimental work. Tube wall is subjected to constant heat flux. Structured grid is used for all cases in this study. Due to symmetric condition along the longitudinal axis, half of the computational domain is considered for the simulations.

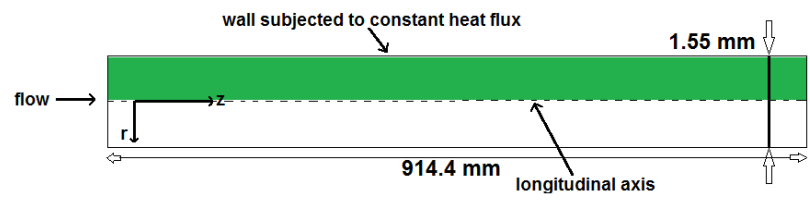

Figure 1. Schematic of the tube that is used for the simulations

Boundary adaption technique is used in order to achieve high accuracy calculations close to the tube wall [23].

\section{GOVERNING EQUATIONS}

Steady-state two-dimensional axisymmetric laminar forced convection of non-Newtonian nanofluids inside a circular plain tube is investigated numerically. Therefore, the equations of mass, momentum and energy conservations are as follows:

$$
\begin{gathered}
\nabla \cdot\left(\rho_{n f} \vec{V}\right)=0 \\
\left(\rho_{n f} \overrightarrow{\boldsymbol{V}} \overrightarrow{\boldsymbol{V}}\right)=-\nabla P+\nabla \cdot\left(\eta_{n f} \nabla \overrightarrow{\boldsymbol{V}}\right) \\
\nabla \cdot\left(\rho_{n f} \overrightarrow{\boldsymbol{V}} c_{n f} T\right)=\nabla \cdot\left(k_{n f} \nabla T\right)
\end{gathered}
$$

where, $\overrightarrow{\boldsymbol{V}}$ is the velocity vector. T and $p$ are the temperature and the pressure, respectively. $\rho_{n f}, \mu_{n f}, C_{n f}, K_{n f}$ are the density, dynamic viscosity, specific heat capacity and thermal conductivity, respectively. Subscript of $n f$ refers to the nanofluid.

Viscosity and thermal conductivity of dispersed Cuo nanoparticles suspended in carboxymethyl cellulose (CMC) with $0.5,1,1.5,3,4 \%$ volume fractions are extracted from Hojjat et al. [7, 8]. They reported the viscosity of nonNewtonian nanofluids in terms of power law and consistency indices for the temperatures of 278, 288, 298, 308 and $318 \mathrm{~K}$ based on the following relation:

$$
\eta=k \dot{\gamma}^{n-1}
$$

where, $\eta$ is apparent viscosity, $k_{\mathrm{o}}$ is the consistency index, $\dot{\gamma}$ is shear rate and $n$ is power-law index. In the present study, Eq. (5) is used to model the viscosity as a function of shear rate and temperature simultaneously:

$$
\eta=C_{I} \dot{\gamma}^{m-1}
$$

$$
C_{I}=k_{0} \exp \left(\alpha_{a c t}\left(\frac{1}{T}-\frac{1}{T_{0}}\right)\right)
$$

where, $m$ is new power law index, $\mathrm{C}_{\mathrm{I}}$ is new consistency index, $\alpha_{\text {act }}$ is the ratio of activation energy and thermodynamic constant and $T_{\mathrm{o}}$ is a reference temperature. Then new values of $k_{\mathrm{o}}, m, \alpha_{\text {act }}$ and $T_{\mathrm{o}}$ are found to adjust Eq. (5) on the experimental data of Hojjat et al. [7] as Table 1 shows. This table shows that new adjusted parameters are in a good agreement with experimental data as $\mathrm{R}^{2}$ is very close to 1 . Figure 2 compares experimental data with the results of present model for volume fraction of $4 \%$

Table 1. Values of $\boldsymbol{k}_{\mathbf{0}}, \mathrm{m}, \alpha_{\mathrm{act}}, T_{\mathrm{o}}$ and $R^{2}$ used in Eq. (5) for volume fractions of $0 \%$ to $4 \%$

\begin{tabular}{cccccc}
\hline $\boldsymbol{\varphi}$ & $\mathrm{m}$ & $k_{\mathrm{o}}$ & $\alpha_{\mathrm{act}}$ & $T_{\mathrm{o}}$ & $R^{2}$ \\
\hline $\mathbf{0}$ & 0.5348 & 0.0782 & 1100.736 & 363.4572 & 0.997 \\
$\mathbf{0 . 5}$ & 0.5306 & 0.0126 & 1251.08 & 741.9133 & 0.998 \\
$\mathbf{1}$ & 0.538 & 0.0333 & 1120.375 & 487.541 & 0.998 \\
$\mathbf{1 . 5}$ & 0.5382 & 0.015 & 1645.9 & 494.9848 & 0.995 \\
$\mathbf{3}$ & 0.5641 & 0.0217 & 1453.774 & 459.8161 & 0.995 \\
$\mathbf{4}$ & 0.5681 & 0.0132 & 1543.877 & 534.9958 & 0.997 \\
\hline
\end{tabular}

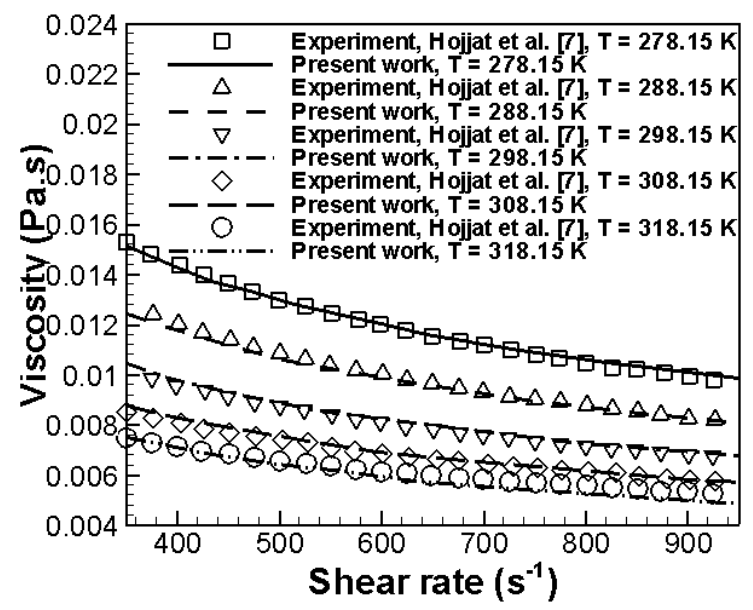

Figure 2. Comparison of experimental data with the results of present model for volume fraction of $4 \%$

Thermal conductivity of nanofluids $\left(K_{n f}\right)$ is also calculated using a fourth degree polynomial function of temperature as follows:

$$
K_{n f}=a T^{4}+b T^{3}+c T^{2}+d T+e
$$

$a, b, c, d$, and $e$ are presented in Table 2 for different volume fractions. $\mathrm{R}^{2}$ which is equal to 1 for all volume fractions showing that the present results are in good agreement with the experimental ones.

The density and specific heat capacity are calculated by Eqns. (7) and (8) which are developed for solid and liquid mixtures as follow:

$$
\begin{gathered}
\rho_{n f}=\varphi \rho_{p}+(1-\varphi) \rho_{b f} \\
C_{n f}=\varphi C_{p}+(1-\varphi) C_{b f}
\end{gathered}
$$

where, $\varphi$ is the volume fraction of nanoparticles and subscripts $p$ and $b f$ refer to nanoparticle and base fluid, respectively. 
Table 2. Constants $a, b, c, d$, e calculated from curve fitting of Eq. (6) on experimental data

\begin{tabular}{ccccccc}
\hline$\varphi$ & $a$ & $b$ & $c$ & $d$ & $e$ & $R^{\mathbf{2}}$ \\
\hline $\mathbf{0}$ & $8.5 \times 10^{-8}$ & $-1.01 \times 10^{-4}$ & $4.49 \times 10^{-2}$ & -8.86 & 656 & 1 \\
$\mathbf{0 . 5}$ & $9.58 \times 10^{-8}$ & $-1.14 \times 10^{-4}$ & $5.10 \times 10^{-2}$ & -1.01 & 752 & 1 \\
$\mathbf{1}$ & $6.21 \times 10^{-8}$ & $-7.31 \times 10^{-5}$ & $3.23 \times 10^{-2}$ & -6.33 & 464.9 & 1 \\
$\mathbf{1 . 5}$ & $1.11 \times 10^{-7}$ & $-1.32 \times 10^{-4}$ & $5.89 \times 10^{-2}$ & 11.7 & 864 & 1 \\
$\mathbf{3}$ & $1.92 \times 10^{-7}$ & $-2.19 \times 10^{-4}$ & $9.38 \times 10^{-2}$ & -17.8 & 1269 & 1 \\
$\mathbf{4}$ & $-4.77 \times 10^{-7}$ & $5.68 \times 10^{-4}$ & $-0.253 \times 10^{-2}$ & 49.9 & -3688 & 1 \\
\hline
\end{tabular}

Reynolds numbers of 600, 900, 1200 and 1500 are used to investigate laminar heat transfer of mentioned nanofluids. Two velocity profiles are considered as inlet boundary condition: hydrodynamically fully developed flow and uniform flow. Thermal entry length condition would exist if the location at which heat transfer begins is preceded by an unheated starting length. A user defined function (UDF) is used to enter non-Newtonian nanofluids with a fully developed velocity profile and avoid adding an unheated computational domain. Constant heat flux of $6000 \mathrm{~W} / \mathrm{m}^{2}$ is subjected on the walls and outflow boundary condition is used for the outlet which means that all the variables have no change at the outlet. All simulations are performed for inlet temperature of $300 \mathrm{~K}$. Since the flow is symmetry, axis boundary condition is used for longitudinal axis (centerline) to assume half of the computational domain. A two-dimensional finite element analysis based on a single-phase fluid system is used to solve the governing equations. Fluid is assumed to be a continuum phase. Pressure and velocity are coupled using SIMPLE algorithm. The PRESTO scheme is used to discretize pressure and second-order upwind scheme to discretize both momentum and energy equations. Convergences are achieved when summation of residuals decreased to $10^{-5}$ for continuity and momentum equations.

\section{RESULTS}

First, some considerations are described before presenting the results. Volume fractions of $0 \%, 0.5 \%, 1 \%, 1.5 \%, 3 \%$ and $4 \%$, the Reynolds numbers of 600, 900, 1200 and 1500, and two inlet boundary conditions (fully developed flow and uniform velocity profile) lead to 48 cases are considered to study laminar convection heat transfer of non-Newtonian nanofluids in the present study. Since there are too many cases and results are identical in trends, one different case is chosen for each section to explain nanofluid behavior.

\subsection{Validation}

Eq. (9) presented by Siginer et al. [24] is used to validate the present simulations. It should be mentioned that this equation is used when fluid is hydrodynamically fully developed before heating.

$$
N u_{z}=1.41 \delta^{1 / 3} G z^{1 / 3}
$$

where,

$$
\begin{aligned}
& \delta=\frac{(3 m+1)}{4 m}, \quad G z=\operatorname{Re} \cdot \operatorname{Pr} \cdot \frac{D}{z} \quad, \quad \operatorname{Re}=\frac{\rho_{n f} U^{2-m} D^{m}}{C_{I}}, \\
& \operatorname{Pr}=\frac{C_{n f} \cdot C_{I}}{K_{n f}}\left(\frac{U}{D}\right)^{m-1}
\end{aligned}
$$

$U$ is the mean velocity of the fluid, $D$ is tube diameter (1.55 $\mathrm{mm}), G z, R e$, and $P r$ are Graetz, Reynolds and Prandtl numbers, respectively and $z$ refers to axial coordinate.

Siginer et al. [24] presented Eq. (10) for power-law nonNewtonian fluids with fully developed velocity profile:

$$
\frac{U_{z}}{U_{\max }}=1-\left(\frac{r}{R}\right)^{\left(\frac{1}{m}\right)+1}
$$

where, subscript max refers to the maximum, $r$ is radial coordinate of the tube and $R$ is tube radius. Accuracy of this equation is shown in section 3.4. Figure 3 shows the Nusselt number of the base fluid (calculated from Eq. (11) using simulation data) and Nusselt number obtained by Eq. (9) at Reynolds numbers of 600 and 1500.

$$
\begin{aligned}
& N u_{z}=\frac{h \cdot D}{K_{n f}} \\
& h=\frac{q^{\prime \prime}}{T_{w}-T_{b}}
\end{aligned}
$$

$h$ is convection heat transfer coefficient, $q^{\prime \prime}$ is the wall heat flux equal to $6000 \mathrm{~W} / \mathrm{m}^{2}, T_{\mathrm{w}}$ is wall temperature along the tube length and $T_{\mathrm{b}}$ is bulk temperature of the fluid. Figure 3 shows a very good agreement between the simulation results and those computed by Eq. (9).

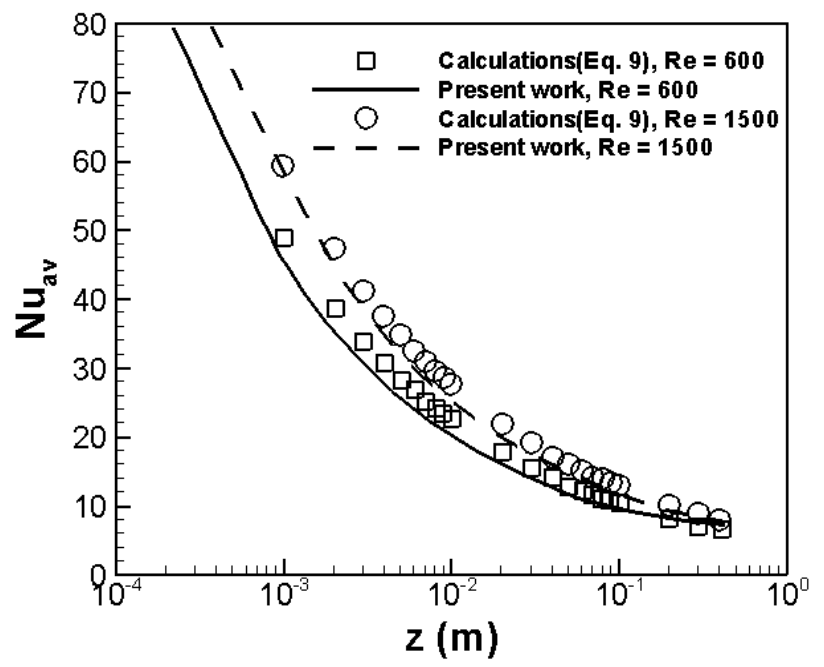

Figure 3. Average Nusselt number obtained from the present simulations and that calculated from Eq. (9) for the base fluid

\subsection{Grid study}

Natural convection of the Base fluid with Reynolds number equals to 600 is considered for four grid resolutions: 41200 
(named as grid 1), 82500 (named as grid 2), 155424 (named as grid 3) and 291250 (named as grid 4). Boundary adaption technic is used for all grid resolutions. Average Nusselt number is calculated using different grid resolutions and presented in Figure 4 to verify which grid resolution can be used for the simulations. It is found that the results correspond to grid 4 and grid 5 are approximately the same. The mean deviation of grid 3 and grid 2 compared to grid 4 is about $1 \%$ and $3 \%$, respectively. Grid 1 is not obviously appropriate to use in order to large deviation compared to grid 4 . Consequently, grid 3 is chosen for further simulations.

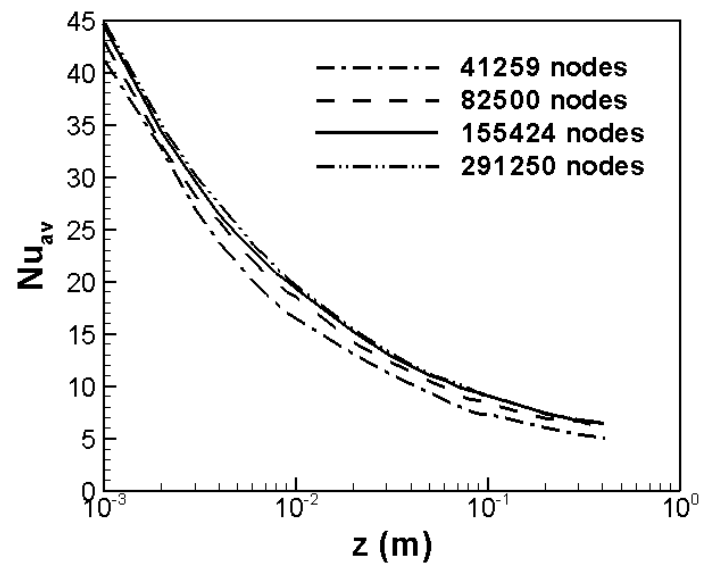

Figure 4. Grid independency verification

\subsection{Viscosity and thermal conductivity profiles along the tube}

As mentioned previously in this paper, viscosity is a function of shear stress and temperature. In addition, thermal conductivity is a function of temperature of nanofluids. In this section, the volume fractions of $3 \%$ and $\mathrm{Re}=1200$ are considered as a case study to discuss about the variations of viscosity and thermal conductivity along the tube. Other volume fractions and Reynolds numbers have the same manner. Figure 5 shows the viscosity profile for the case study using fully developed velocity profile as the inlet boundary condition.

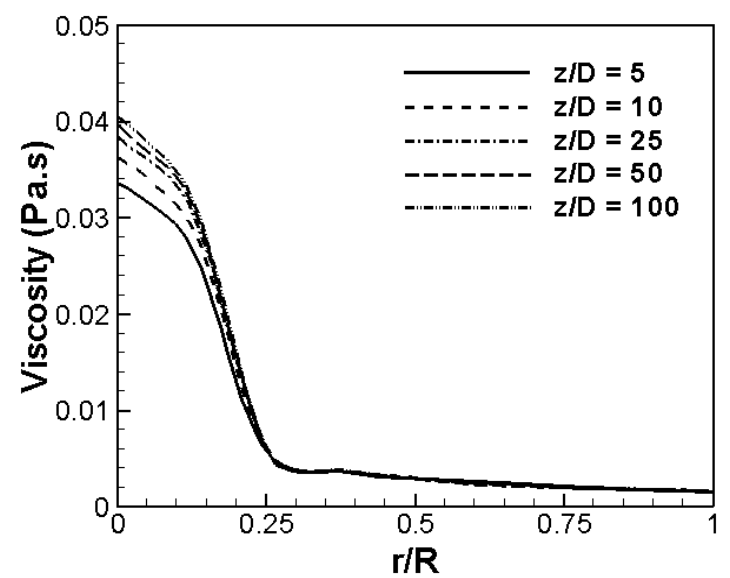

Figure 5. Viscosity profile along the tube for the volume fraction of $3 \%$ at $\operatorname{Re}=1200$ for fully developed flow as inlet boundary condition

Figure 5 shows that there are little changes in viscosity profile along the tube and all the profiles has the same trend which is due to fully development before heating. Normally viscosity of the fluid decreases near the heating wall. Upper temperature makes lower viscosity. At the middle of the tube, lower temperature leads to higher viscosity. Figure 6 shows the viscosity profile of the case study when a uniform velocity profile is assumed as the inlet boundary condition. There are large changes in the viscosity profile along the tube because the fluid is going to be fully developed hydrodynamically and thermally simultaneously. There is also low viscosity near the tube wall and high viscosity at the center of the tube because of more shear stress and temperature at the wall. Along the tube, at $\mathrm{z} / \mathrm{D}=100$, the flow is fully developed and viscosity profile has a trend like viscosity profiles presented in Figure 5 which means that the flow is fully developed at this point.

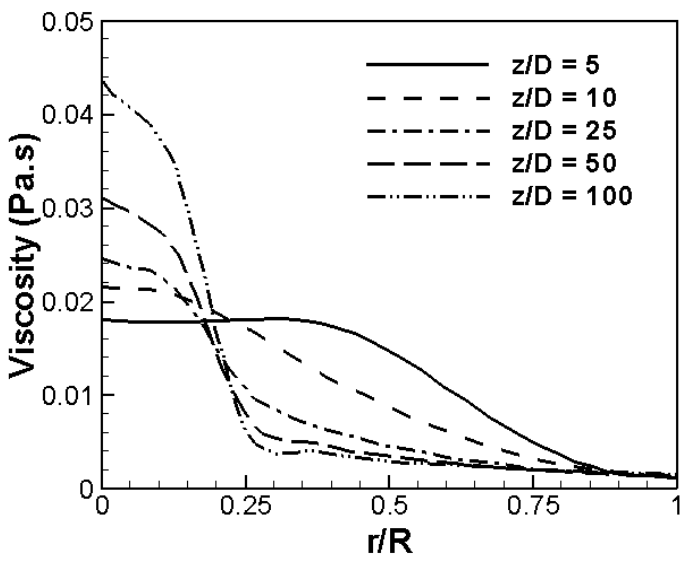

Figure 6. Viscosity profile along the tube for volume fraction of $3 \%$ at $\operatorname{Re}=1200$ for uniform flow as inlet boundary condition

Thermal conductivity is more predictable in comparison with the viscosity. It is a decreasing function of temperature. It means that higher temperature results in larger thermal conductivity. Figure 7 shows thermal conductivity profiles along the tube for the case study. Kamali and Binesh presented the same trend for the thermal conductivity [22].

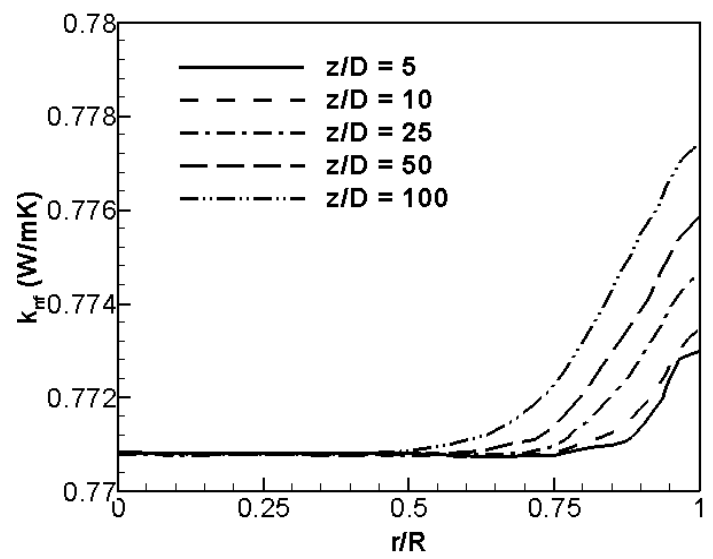

Figure 7. Thermal conductivity profile for volume fraction of $3 \%$ at $\mathrm{Re}=1200$

\subsection{Local heat transfer coefficient}

Reynolds number, volume fraction of nanopraticles and velocity profile of inlet flow are effective parameters on heat transfer coefficient. A new case study is selected to verify how 
velocity profile impacts on local heat transfer. Local heat transfer is calculated by using Eq. (12). In this case, Reynolds number and volume fraction of nanofluid are kept constant at 900 and $4 \%$, respectively. Figure 8 shows that the Nusselt number of fully developed flow is less than that of uniform flow. However, the Nusselt Number along the tube (almost at $\mathrm{z} / \mathrm{L}=10$ ) is identical for two boundary conditions because uniform velocity profile goes to be fully developed along the tube (Figure 9). At this point, the velocity becomes fully developed and has little changes in comparison with the point at $\mathrm{z} / \mathrm{L}=0.15$. Figure 9 also shows the velocity profile predicted by Eq. (10) for the case study. There is just $2.5 \%$ of mean deviation with point $\mathrm{z} / \mathrm{L}=0.15$ considering that the flow is fully developed at this point.

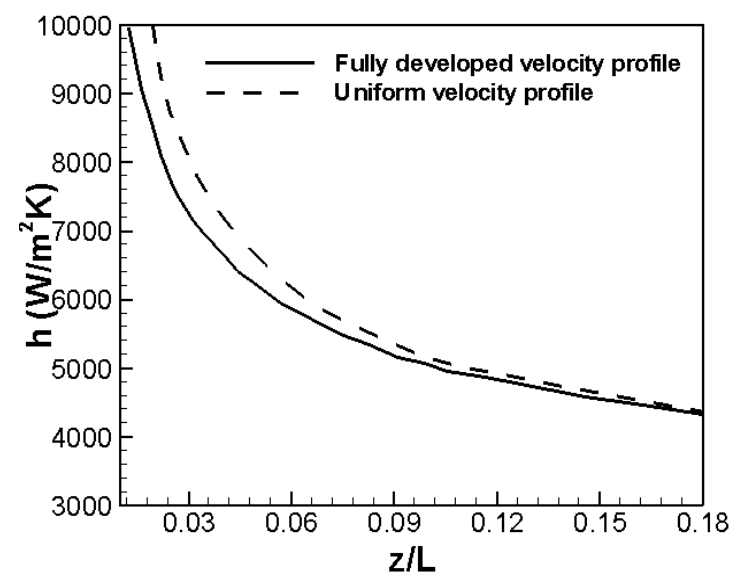

Figure 8. Comparison of local heat transfer coefficient for fully developed flow and uniform flow at $\mathrm{Re}=900$ and volume fraction of $4 \%$

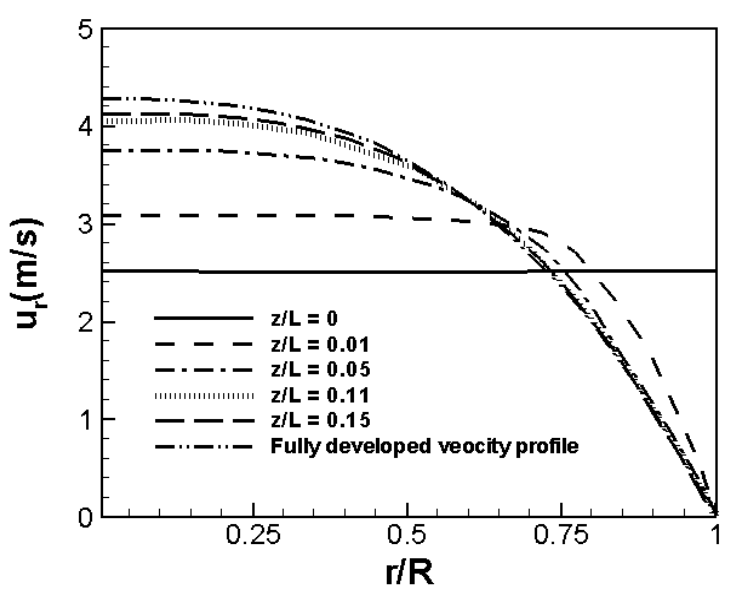

Figure 9. Radial component of the velocity along the tube

Figure 10 shows the effect of volume fraction of nanoparticle on local heat transfer coefficient for the case of Reynolds number equals to 900 for fully developed flow.

As previous researchers reported, an increase in the volume fraction of nanoparticles leads to an increase in the heat transfer coefficient [7, 8, 14-16]. Here, the heat transfer coefficient does not increase for the volume fractions less than $3 \%$. Figure 11 shows that there is the same trend for uniform flow.

The influence of Reynolds number on local heat transfer is shown in Figure 12 and Figure 13 for fully developed and uniform flows, respectively.

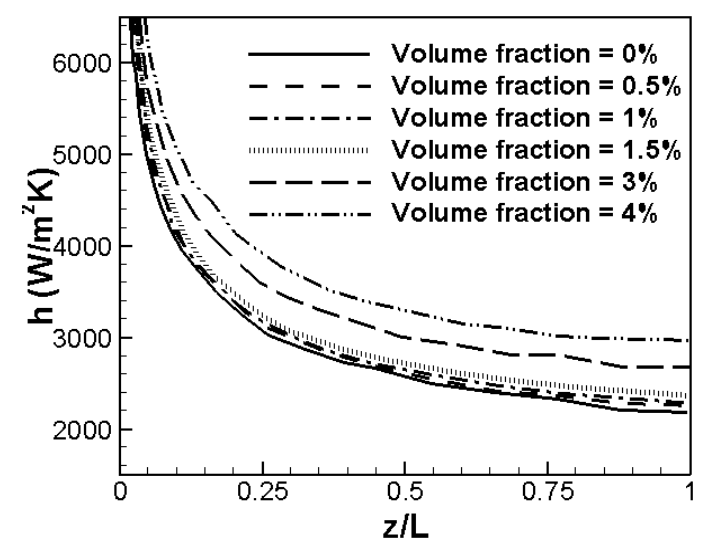

Figure 10. Local heat transfer coefficient at $\mathrm{Re}=900$ for fully developed flow boundary condition and different volume fractions of nanoparticles

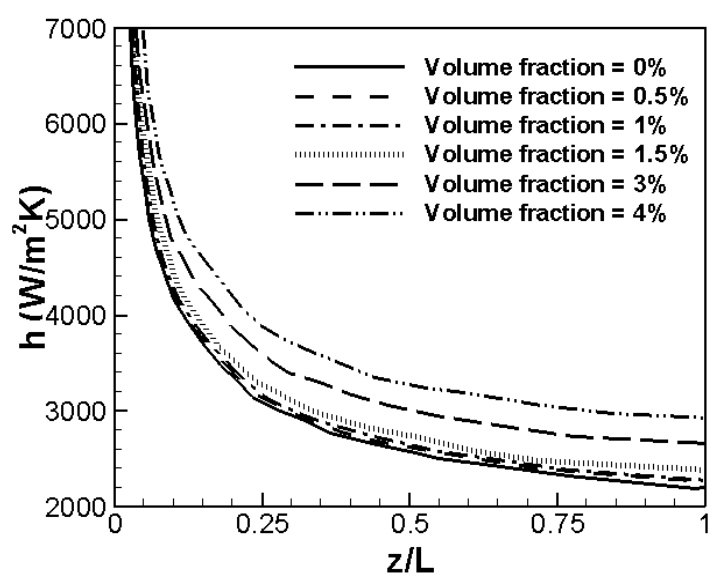

Figure 11. Local heat transfer coefficient at $\mathrm{Re}=900$ for uniform flow boundary condition and different volume fractions of nanoparticles

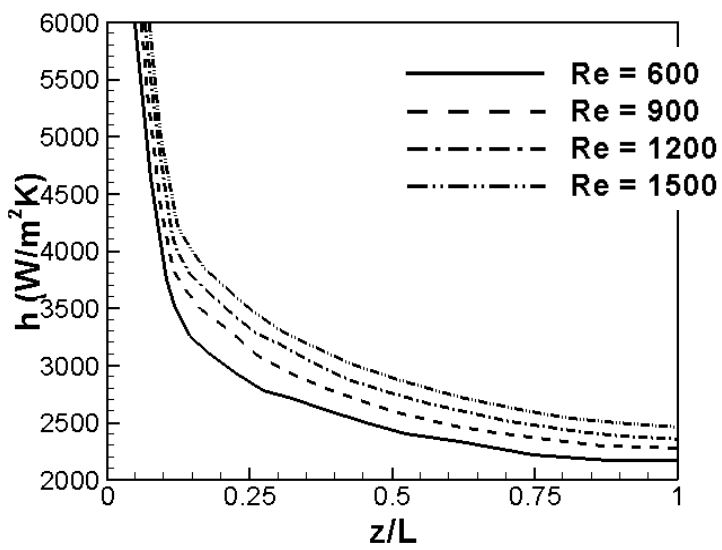

Figure 12. Local heat transfer coefficient for different Reynolds numbers and volume fraction of $1 \%$ for fully developed flow

It is concluded that the heat transfer coefficient increases with the Reynolds number. An increase in the Reynolds number makes the fluid flow faster leads to more effective contacts to heating wall, more distribution of heat, more bulk temperature and then less wall temperature. As the difference of wall and bulk temperature decreases in Eq. (12), the heat transfer coefficient increases. Many previous researches confirm this conclusion [22]. 


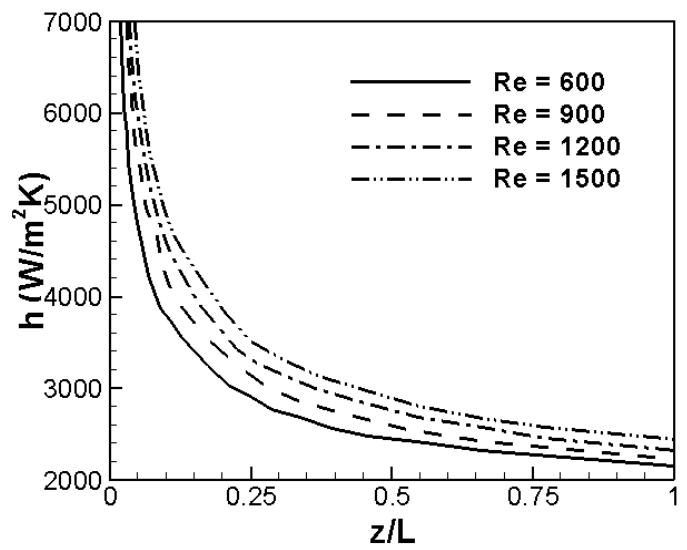

Figure 13. Local heat transfer coefficient for different Reynolds numbers and volume fraction of $1 \%$ for uniform flow

\subsection{Average Nusselt number}

Average Nusselt number is calculated using Eq. (13):

$$
\begin{gathered}
N u_{a v}=\frac{\bar{h} \cdot D}{\left.K_{n f}\right|_{@ 298 k}} \\
\bar{h}=\frac{q^{\prime \prime}}{\bar{T}_{w}-\bar{T}_{b}}
\end{gathered}
$$

where, $\bar{T}_{w}, \bar{T}_{b}$ are average bulk and wall temperatures, respectively. $\bar{h}$ refers to average heat transfer coefficient and $N u_{a v}$ is the average Nusselt number. As mentioned before, thermal conductivity of the nanofluids is a function of temperature. Because there is a temperature distribution all over the tube, it is not possible to assume a constant thermal conductivity for a nanofluid.

Figures 14 and 15 show average Nusselt number for various Reynolds numbers and volume fractions for fully developed and uniform flows, respectively.

Besides, Figure 16 illustrates thermal diffusion coefficient as a function of volume fraction. It is found that thermal diffusion coefficient is enhanced by increasing the volume fraction of nanoparticles.

Figure 14 and Figure 15 show that the average Nusselt number decreases by increasing the volume fraction. However, the heat transfer coefficient increases with the volume fraction. This is due to the Prandtl number of the nanofluids. Previous researchers often reported that the Nusselt number is a function of Reynolds and Prandtl numbers as follows [23]:

$$
N u=A_{1} \operatorname{Re}^{A_{2}} \cdot \operatorname{Pr}^{A_{3}}
$$

where, $A_{1}, A_{2}$, and $A_{3}$ are empirical constants and are different for various cases. In order to study the effect of Reynolds and Prandtl numbers on average Nusselt number, Peclet number which is equivalent to the product of the Reynolds number and the Prandtl number is used. Therefore, Nusselt number is assumed to be a function of Peclet number.

$$
P e=\operatorname{Re} \cdot \operatorname{Pr}=\frac{\rho_{n f} U^{2-m} D^{m}}{C_{I}} \cdot \frac{C_{n f} \cdot C_{I}}{\left.K_{n f}\right|_{@ 298 k}}\left(\frac{U}{D}\right)^{m-1}=\frac{\rho_{n f} U D C_{n f}}{\left.K_{n f}\right|_{@ 298 k}}
$$

Considering $\alpha$ as heat diffusion coefficient:

$$
a=\frac{\left.K_{n f}\right|_{@ 298 k}}{\rho_{n f} C_{n f}}
$$

the Peclet number is defined as:

$$
P e=\frac{U D}{a}
$$

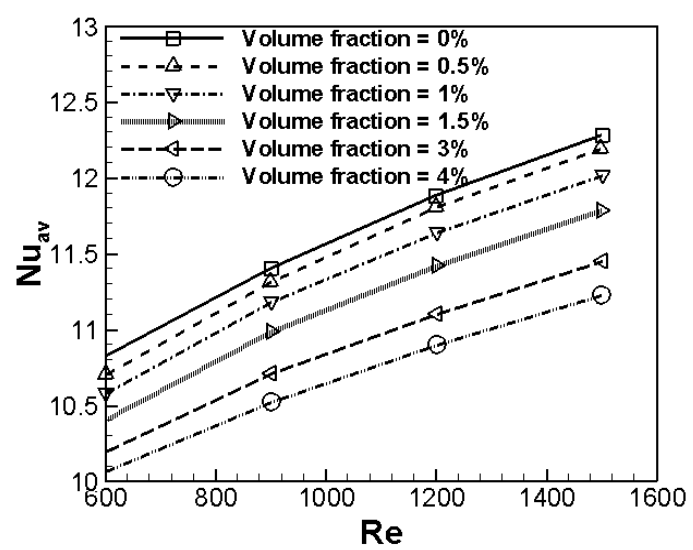

Figure 14. Average Nusselt number for different Reynolds numbers and volume fractions for fully developed flow as inlet boundary conditions

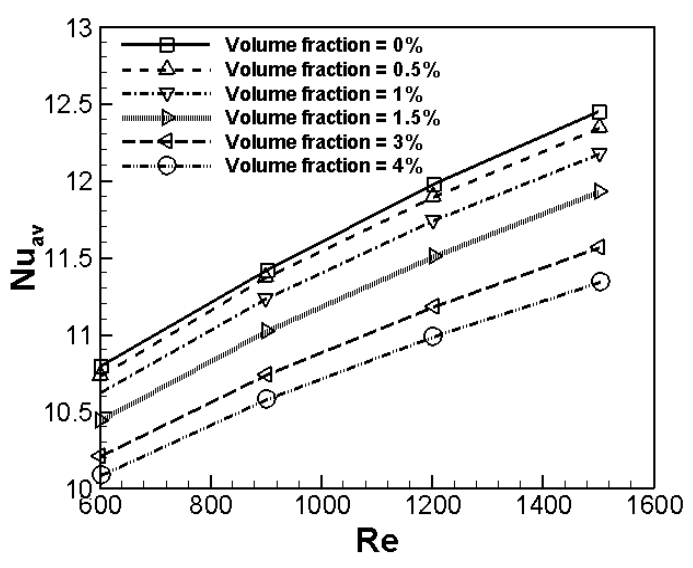

Figure 15. Average Nusselt number for different Reynolds numbers and volume fractions for uniform flow as inlet boundary conditions

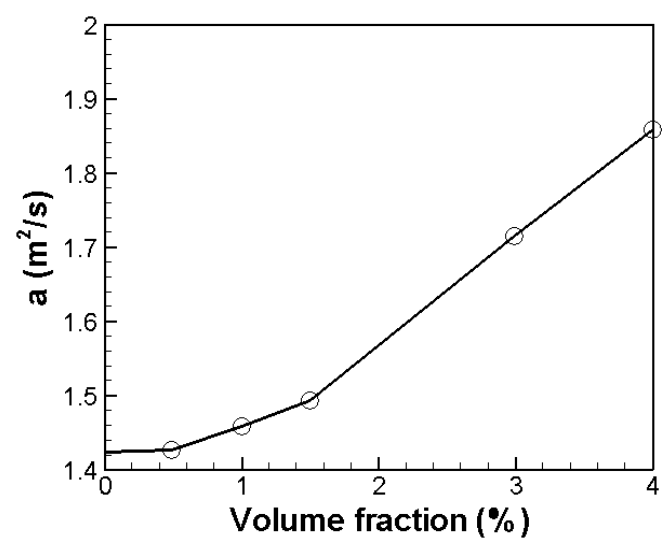

Figure 16. Thermal diffusion coefficient versus volume fraction for $\mathrm{Re}=600$ 
Peclet number is an inverse function of diffusion coefficient of nanofluid and depends on average flow velocity and tube diameter. Hence, Peclet number does not vary for fully developed flow in comparison with the uniform flow. Figure 17 shows diffusion coefficient of the nanofluid for volume fractions of $0 \%$ to $4 \%$. Thermal diffusion coefficient is decreasing function of volume fraction of nanofluid. It is the reason of descending trend of Peclet number as a function of volume fraction. As a result, Nusselt number is a function of Peclet number:

$$
N u=C_{1}\left(1+C_{2} \cdot \phi\right) P e^{C_{3}}
$$

where, $\mathrm{C}_{1}, \mathrm{C}_{2}, \mathrm{C}_{3}$ are constants and $\varphi$ is volume concentration of nanofluid. Table 3 shows mentioned constants for both inlet boundary conditions. Figures 18 and 19 show exact predictions of Nusselt number of the nanofluid for fully developed and uniform flows, respectively using Eq. (16). Mean deviations of the predictions are $0.5 \%$ and $0.4 \%$ in Figures 17 and 18, respectively.

Table 3. Constants $\mathrm{C}_{1}, \mathrm{C}_{2}$, and $\mathrm{C}_{3}$ for Eq. (16)

\begin{tabular}{lcc}
\hline & Fully developed flow & Uniform flow \\
\hline $\mathbf{C}_{\mathbf{1}}$ & 1.3739 & 1.3169 \\
$\mathbf{C}_{\mathbf{2}}$ & 0.3590 & 0.2928 \\
$\mathbf{C}_{\mathbf{3}}$ & 0.2056 & 0.2107 \\
\hline
\end{tabular}

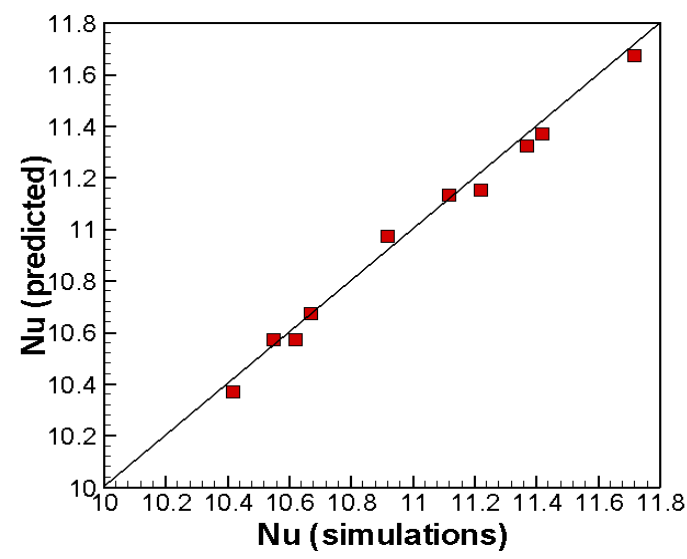

Figure 17. The Nusselt number obtained from the present simulations and predicted by Eq. (16) for fully developed flow as inlet boundary condition

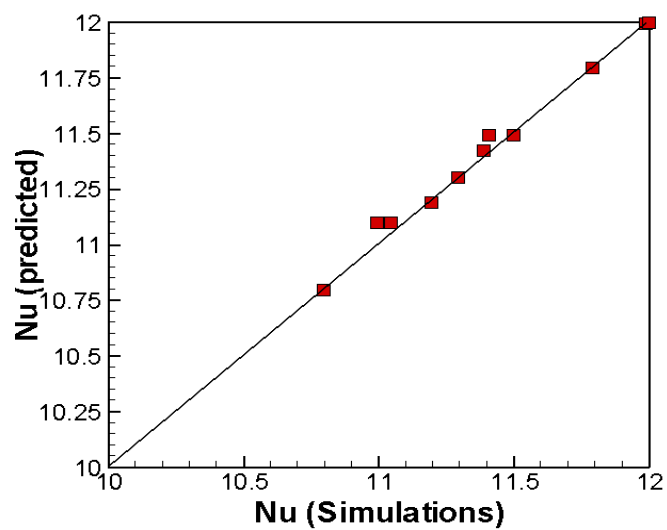

Figure 18. The Nusselt number obtained from the present simulations and predicted by Eq. (16) for uniform flow as inlet boundary condition

\section{CONCLUSIONS}

In this study, thermal and rheological properties of Cuo/carboxymethyl cellulose (CMC) non-Newtonian nanofluids were studied for volume fractions of 0 (base fluid), $0.5,1,1.5,3,4 \%$. A new model was presented to predict viscosity of the nanofluids as a function of temperature and shear stress simultaneously. Thermal conductivity of the nanofluids was a function of temperature under constant heat flux in a tube. Fully developed velocity and uniform velocity profiles were used as inlet boundary condition to verify how fully developed flow impacts on heat transfer of the nanofluids. It was found that viscosity variations along the tube is affected by temperature for fully developed flow and affected by shear stress for uniform flow. The results revealed that local heat transfer for fully developed flow is less than that for uniform flow until uniform velocity profile reaches fully developed one. Local heat transfer coefficient along the tube increases with the volume fraction, however volume fraction less than $3 \%$ does not affect local heat transfer. It was demonstrated that local heat transfer and average Nusselt number are decreasing functions of Reynolds number. Contrary to previous researches, the present results showed that the average Nusselt number is a descending function of volume fraction of nanoparticles due to the Prantdl number effect. Hence, Peclet number was proposed to evaluate the effects of Reynolds and Prantdl numbers on average Nusselt number. Hence, the Nusselt number was suggested to be a function of Peclet number. Thermal diffusion coefficient increases with the volume fraction of nanoparticles and decreases with the Peclet number. This is the main reason of descending trend of average Nusselt number as the volume fraction of nanoparticles increases.

\section{REFERENCES}

[1] Das, S.K., Choi, S.U.S., Yu, W., Pradeep, T. (2008). Nanofluid: Science and Technology. John Wiley, New York.

[2] Shirazi, M., Shateri, A., Bayareh, M. (2018). Numerical investigation of mixed convection heat transfer of a nanofluid in a circular enclosure with a rotating inner cylinder. Journal of Thermal Analysis and Calorimetry, 133(2): 1061-1073. http://dx.doi.org/10.1007/s10973018-7186-y

[3] Utomo, A.T., Poth, H., Robbins, P.T., Pacek, A.W. (2012). Experimental and theoretical studies of thermal conductivity, viscosity and heat transfer coefficient of Titania and alumina nanofluids. International Journal of Heat and Mass Transfer, 55(25-26): 7772-7781. http://dx.doi.org/10.1016/j.ijheatmasstransfer.2012.08.0 03

[4] Gu, B., Hou, B., Lu, Z., Wang, Z., Chen, S. (2013). Thermal conductivity of nanofluids containing high aspect ratio fillers. International Journal of Heat and Mass Transfer, 64: 108-114. http://dx.doi.org/10.1016/j.ijheatmasstransfer.2013.03.0 80

[5] Li, F.C., Yang, J.C., Zhou, W.W., He, Y.R., Huang, Y.M., Jiang, B.C. (2013). Experimental study on the characteristics of thermal conductivity and shear viscosity of viscoelastic-fluid-based nanofluids containing multi-walled carbon nanotubes. 
Thermochimica

Acta,

$556:$

47-53.

http://dx.doi.org/10.1016/j.tca.2013.01.023

[6] Halelfadl, S., Estellé, P., Aladag, B., Doner, N., Maré, T. (2013). Viscosity of carbon nanotubes water-based nanofluids: Influence of concentration and temperature. International Journal of Thermal Sciences, 71: 111-117. http://dx.doi.org/10.1016/j.ijthermalsci.2013.04.013

[7] Hojjat, M., Etemad, S.G., Bagheri, R., Thibault, J. (2011). Rheological characteristics of non-Newtonian nanofluids: Experimental investigation. International Communications in Heat and Mass Transfer, 38(2): 144148.

http://dx.doi.org/10.1016/j.icheatmasstransfer.2010.11.0 19

[8] Hojjat, M., Etemad, S.G., Bagheri, R., Thibault, J. (2011). Thermal conductivity of non-Newtonian nanofluids: Experimental data and modeling using neural network. International Journal of Heat and Mass Transfer, 54(5-6): 1017-1023.

http://dx.doi.org/10.1016/j.ijheatmasstransfer.2010.11.0 39

[9] Mariano, A., Pastoriza-Gallego, M.J., Lugo, L., Camacho, A., Canzonieri, S., Pineiro, M.M. (2013). Thermal conductivity, rheological behaviour and density of non-Newtonian ethylene glycol-based $\mathrm{SnO}_{2}$ nanofluids. Fluid Phase Equilibria, 337: 119-124. http://dx.doi.org/10.1016/j.fluid.2012.09.029

[10] Garg, P., Alvarado, J.L., Marsh, C., Carlson, T.A., Kessler, D.A., Annamalai, K. (2009) An experimental study on the effect of ultrasonication on viscosity and heat transfer performance of multi-wall carbon nanotubebased aqueous nanofluids. International Journal of Heat and Mass Transfer, 52: 5090-5101. http://dx.doi.org/10.1016/j.ijheatmasstransfer.2009.04.0 29

[11] Labib, M.N., Nine, M.J., Afrianto, H., Chung, H., Jeong, H. (2013). Numerical investigation on effect of base fluids and hybrid nanofluid in forced convective heat transfer. International Journal of Thermal Sciences, 71: 163-171. https://doi.org/10.1016/j.ijthermalsci.2013.04.003

[12] Esmaeilnejad, A., Aminfar, H., Shafiee Neistanak, M. (2014) Numerical investigation of forced convection heat transfer through microchannels with non-Newtonian nanofluids. International Journal of Thermal Sciences, 75 : 76-86. https://doi.org/10.1016/j.ijthermalsci.2013.07.020

[13] Sepyani, M., Shateri, A., Bayareh, M. (2019). Investigating the mixed convection heat transfer of a nanofluid in a square chamber with a rotating blade. Journal of Thermal Analysis and Calorimetry, 135: 609623. http://dx.doi.org/10.1007/s10973-018-7098-x

[14] Jahanbakhshi, A., Ahmadi Nadooshan, A., Bayareh, M. (2018). Magnetic field effects on natural convection flow of a non-Newtonian fluid in an L-shaped enclosure. Journal of Thermal Analysis and Calorimetry, 133: 14071416. http://dx.doi.org/10.1007/s10973-018-7219-6

[15] ZeinaliHeris, S., Nasr Esfahany, M., Etemad, S.G. (2007). Experimental investigation of convective heat transfer of $\mathrm{A}_{2} \mathrm{O}_{3}$ /water nanofluid in circular tube. International Journal of Heat and Fluid Flow, 28: 203-211. http://dx.doi.org/10.2298/TSCI181010414M

[16] Bayareh, M., Kianfar, A., Kasaeipour, A. (2018). Mixed convection heat transfer of water-alumina nanofluid in an

inclined and baffled C-shaped enclosure. Journal of Heat and Mass Transfer Research, 5(2): 129-138. https://doi.org/10.22075/jhmtr.2018.13390.1196

[17] Hojjat, M., Etemad, S.G., Bagheri, R., Thibault, J. (2011). Convective heat transfer of non-Newtonian nanofluids through a uniformly heated circular tube. International Journal of Thermal Sciences, 50(4): 525-531. http://dx.doi.org/10.1016/j.ijthermalsci.2010.11.006

[18] Keshavarz Moraveji, M., Haddad, S.M.H., Darabi, M. (2012). Modeling of forced convective heat transfer of a non-Newtonian nanofluid in the horizontal tube under constant heat flux with computational fluid dynamics. International Communications in Heat and Mass Transfer, 39(7): 995-999. https://doi.org/10.1016/j.icheatmasstransfer.2012.05.00 3

[19] Ahmed, M.A., Yusoff, M.Z., Shuaib, N.H. (2013). Effects of geometrical parameters on the flow and heat transfer characteristics in trapezoidal-corrugated channel using nanofluid. International Communications in Heat and Mass Transfer, 42: 69-74. https://doi.org/10.1016/j.icheatmasstransfer.2012.12.01 2

[20] Wongcharee, K., Eiamsa-ard, S. (2012). Heat transfer enhancement by using $\mathrm{CuO} /$ water nanofluid in corrugated tube equipped with twisted tape. International Communications in Heat and Mass Transfer, 39(2): 251257.

https://doi.org/10.1016/j.icheatmasstransfer.2011.11.01 0

[21] Ahmed, M.A., Shuaib, N.H., Yusoff, M.Z., Al-Falahi, A.H. (2011). Numerical investigations of flow and heat transfer enhancement in a corrugated channel using nanofluid. International Communications in Heat and Mass Transfer, 38(10): 1368-1375. https://doi.org/10.1016/j.icheatmasstransfer.2011.08.01 3

[22] Kamali, R., Binesh, A.R. (2010). Numerical investigation of heat transfer enhancement using carbon nanotube-based non-Newtonian nanofluids. International Communications in Heat and Mass Transfer, 37(8): 1153-1157. https://doi.org/10.1016/j.icheatmasstransfer.2010.06.00 1

[23] Bayareh, M., Nasr Esfahany, M., Afshar, N., Bastegani M. (2020). Numerical study of slug flow heat transfer in microchannels. International Journal of Thermal Sciences, 147: 106-118. http://dx.doi.org/10.1016/j.ijthermalsci.2019.106118

[24] Siginer, D.A., Kee, D.D., Chhabra, R.P. (1999). Advances in Flow and Rheology of Non-Newtonian Fluids. 8th edition, Elsevier, Netherlands.

\section{NOMENCLATURE}

$\mathrm{C}$

$\mathrm{p}$

$\mathrm{q}^{\prime \prime}$

$\mathrm{Re}$
$\mathrm{Pr}$

$\mathrm{Pr}$

$\mathrm{Gz}$

V
Heat capacity

Pressure $(\mathrm{Pa})$

heat flux $\left(\mathrm{W} / \mathrm{m}^{2}\right)$

Reynolds number

Prandtl number

Graetz number

Temperature (K)

Velocity vector $(\mathrm{m} / \mathrm{s})$ 


$\begin{array}{ll}\mathrm{k} & \text { Consistency index } \\ \mathrm{n} & \text { Power-law index } \\ K & \text { Thermal conductivity }(\mathrm{W} / \mathrm{m} . \mathrm{K}) \\ U & \text { Mean velocity }(\mathrm{m} / \mathrm{s}) \\ T_{0} & \text { Reference temperature }(\mathrm{K}) \\ C_{I} & \text { New consistency index } \\ D & \text { Tube diameter }(1.55 \mathrm{~mm}) \\ R & \text { Tube radius }(0.775 \mathrm{~mm}) \\ h & \text { Convectional heat transfer coefficient } \\ L & \left.\text { (W/m }{ }^{2} . \mathrm{K}\right) \\ \mathrm{Pe} & \text { Tube length }(\mathrm{m}) \\ & \text { Peclet number }\end{array}$

$\rho$

\section{Subscripts}

$\begin{array}{cl}\text { nf } & \text { Nanofluid } \\ \text { bf } & \text { Base fluid } \\ \mathrm{p} & \text { Nanoparticle } \\ \mathrm{z} & \text { Axial coordinate } \\ r & \text { Radial coordinate } \\ \mathrm{w} & \text { Wall } \\ \mathrm{b} & \text { Bulk }\end{array}$

Density $\left(\mathrm{kg} / \mathrm{m}^{3}\right)$

Shear rate

Volume fraction

Bulk
Non-Newtonian viscosity (Pa.s)

Ratio of activation energy to

thermodynamic constant

Heat diffusion coefficient $\left(\mathrm{m}^{2} / \mathrm{s}\right)$

\section{Greek symbols}

Viscosity (Pa.s)
Peclet number 